\title{
Greenland and Antarctica Ice Sheet Mass Changes and Effects on Global Sea Level
}

\author{
Forsberg, René; Sørensen, Louise Sandberg; Simonsen, Sebastian Bjerregaard
}

Published in:

Surveys in Geophysics

Link to article, DOI:

10.1007/s10712-016-9398-7

Publication date:

2017

Document Version

Peer reviewed version

Link back to DTU Orbit

Citation (APA):

Forsberg, R., Sørensen, L. S., \& Simonsen, S. B. (2017). Greenland and Antarctica Ice Sheet Mass Changes and Effects on Global Sea Level. Surveys in Geophysics, 38, 89-104. https://doi.org/10.1007/s10712-016-93987

\section{General rights}

Copyright and moral rights for the publications made accessible in the public portal are retained by the authors and/or other copyright owners and it is a condition of accessing publications that users recognise and abide by the legal requirements associated with these rights.

- Users may download and print one copy of any publication from the public portal for the purpose of private study or research.

- You may not further distribute the material or use it for any profit-making activity or commercial gain

- You may freely distribute the URL identifying the publication in the public portal 


\title{
Sea level change contributions from the Greenland and Antarctica ice sheets
}

\author{
Rene Forsberg, Louise Sørensen, Sebastian Simonsen \\ National Space Institute, Technical University of Denmark (DTU Space) \\ Elektrovej 328, 2800 Lyngby, Denmark.rf@space.dtu.dk
}

\begin{abstract}
Thirteen years of GRACE data provide an excellent picture of the current mass changes of Greenland and Antarctica, with mass loss in the GRACE period 2002-15 amounting to $265 \pm 25$ GT/yr for Greenland (including peripheral ice caps), and 95 \pm 50 GT/year for Antarctica, corresponding to $0.72 \mathrm{~mm} /$ year and $0.26 \mathrm{~mm} /$ year average global sea level change. A significant acceleration in mass loss rate is found, especially for Antarctica, while Greenland mass loss, after a corresponding acceleration period, and a record mass loss in the summer of 2012, has seen a slight decrease in short-term mass loss trend. The yearly mass balance estimates, based on pointmass inversion methods, have relatively large errors, both due to uncertainties in the glacial isostatic adjustment (GIA) processes, especially for Antarctica, leakage from unmodelled ocean mass changes, and (for Greenland) difficulties in separating mass signals from the Greenland ice sheet and the adjacent Canadian ice caps. The limited resolution of GRACE affects the uncertainty of total mass loss to a smaller degree; we illustrate the "real" sources of mass changes by including satellite altimetry elevation change results in a joint inversion with GRACE, showing that mass change occurs primarily associated with major outlet glaciers, as well as a narrow coastal band. For Antarctica the primary changes are associated with the major outlet glaciers in West Antarctica (Pine Island and Thwaites glacier systems), as well as on the Antarctic Peninsula, where major glacier accelerations have been observed after the 2002 collapse of the Larsen B Ice Shelf.
\end{abstract}

Keywords. Greenland ice sheet, Antarctica mass loss, GRACE, EnviSat, CryoSat

\section{Introduction}

The melting of the polar ice sheets is a major global concern, especially due to the direct effects on global sea level rise. Although estimation of ice sheet mass balance has been a main goal of glaciological research for decades, reliable observations of current mass changes have only been available since the advent of space observations. Three types of Earth observation methods are in 
use for this purpose: satellite altimetry, where direct measurements of height changes by laser (ICESat) or radar (ERS-1/-2, EnviSat, CryoSat-2) altimetry, in combination with climatological/glaciological models for firn (snow) density and compaction, are used to estimate mass loss; input-output methods, where measurements of ice flow velocities from synthetic aperture radar data (ERS, EnviSat, RadarSat) over outlet glaciers are combined with glacier thickness data and models for accumulation and surface mass balance in the interior are used to give a net mass balance; and gravity field change missions (GRACE), where the mass changes are measured directly.

Numerous scientific papers on ice sheet change estimation have been published in the recent decade, and a review and intercomparison of all methods were done in the ESA/NASA supported IMBIE study (Icesheet Mass Balance Intercomparison Experiment 2011-12), resulting in a landmark paper with nearly 50 co-authors (Shepherd et al., 2012). We therefore refer readers to this paper, and extensive references therein, for background on the ice sheet mass loss estimation methods. The main IMBIE conclusions were that the three space-based methods give consistent results, when properly applied for common periods; and that combinations of all methods yield more reliable estimates, with overall mass change estimates closely mirroring GRACE-only estimations.

All the above space-based estimation schemes are affected by various types of errors. Conventional pulse-limited radar satellite altimetry does not cover the most sloping and rugged parts of the icesheets, which are the most rapidly changing parts; furthermore radar altimetry is strongly affected by radar penetration into snow and melt events forming ice lenses in the snowpack, especially in Greenland (Nilsson et al, 2015). The input-output method is limited by lack of information on outlet glacier ice thickness, especially in Antarctica, as well as uncertainty in interior surface mass balance models, derived from regional climate models. GRACE accuracy is limited by signal leakage from adjacent ice caps, land hydrology, unmodelled ocean mass changes, and - especially for Antarctica - large uncertainty in glacial isostatic adjustment (GIA) models (Wahr et al, 1998).

The mass loss of the ice sheets is typically expressed in units of GT/yr, with $100 \mathrm{GT}$ of mass change corresponding to an average global sea level rise of $0.272 \mathrm{~mm} / \mathrm{yr}$. Examples of recent estimates of mass loss and corresponding sea level rise are outlined in Table 1, mainly extracted from a compilation of Dieng et al. (2015). A large variability in results are found, mainly due to use of linear trends over different time intervals; the use of such trends is not very suitable for longer 
time series, where decadal changes in climate and ocean temperatures (a major cause of outlet glacier melt, both in Greenland and Antarctica; Holland et. al, 2008) would be expected to change ice sheet mass loss correspondingly. It should be noted that the mass loss of the ice sheets does not result in a uniform sea level rise; due to changes in gravitation, land uplift and earth rheology, Greenland melt will mainly affect tropical and southern latitudes, while Antarctica melt will mainly affect the northern hemisphere, as illustrated in Fig. 1.

Table 1. Some selected mass loss estimates of the ice sheets by different methods

\begin{tabular}{|c|c|c|c|c|c|c|c|}
\hline \multirow[t]{2}{*}{ Area } & \multirow[t]{2}{*}{ Period } & \multirow[t]{2}{*}{ Method } & \multicolumn{2}{|c|}{ Mass loss } & \multicolumn{2}{|c|}{ Error estimate } & \multirow[t]{2}{*}{ Reference } \\
\hline & & & GT/yr & $\mathrm{mm} / \mathrm{yr}$ & GT/yr & $\mathrm{mm} / \mathrm{yr}$ & \\
\hline \multirow[t]{9}{*}{ Greenland } & $2000-11$ & Combination & 217 & 0.59 & 36 & 0.1 & Shepherd et al., 2012 \\
\hline & $2005-06$ & Input-output & 210 & 0.57 & 40 & 0.11 & Rignot and Kanagaratnam, 2006 \\
\hline & 2003-07 & Altimetry & 176 & 0.48 & 4 & 0.01 & Zwally et al., 2011 \\
\hline & 2003-08 & Altimetry & 239 & 0.65 & 29 & 0.08 & Sørensen et al., 2011 \\
\hline & 2003-08 & Alt. + GRACE & 180 & 0.5 & 29 & 0.08 & Ewert et al., 2012 \\
\hline & 2003-09 & Combination & 265 & 0.72 & 58 & 0.16 & Sasgen et al., 2012 \\
\hline & $2003-10$ & GRACE & 230 & 0.63 & 12 & 0.03 & Lutsche and Sabaka, 2013 \\
\hline & $2003-12$ & GRACE & 265 & 0.72 & 40 & 0.11 & Velicogna and Wahr, 2013 \\
\hline & 2003-12 & GRACE & 235 & 0.64 & 25 & 0.07 & Groh et al., 2014 \\
\hline \multirow[t]{7}{*}{ Antarctica } & 2000-11 & Combination & 88 & 0.24 & 44 & 0.12 & Shepherd et al., 2012 \\
\hline & 2003-09 & Altimetry & 63 & 0.17 & 44 & 0.12 & Helm et al., 2014 \\
\hline & 2010-13 & Altimetry & 159 & 0.43 & 48 & 0.13 & McMillan et al., 2014 \\
\hline & 2003-11 & GRACE & 85 & 0.23 & 36 & 0.1 & Barletta et al., 2013 \\
\hline & 2003-10 & GRACE & 80 & 0.21 & 26 & 0.07 & Lutsche and Sabaka, 2013 \\
\hline & 2003-12 & GRACE & 118 & 0.32 & 66 & 0.18 & Velicogna and Wahr, 2013 \\
\hline & 2003-12 & GRACE & 110 & 0.3 & 29 & 0.08 & Groh et al., 2014 \\
\hline
\end{tabular}

\section{GRACE measurements of ice sheet changes}

For the investigations of this paper we will focus on the GRACE mission mass loss estimates, reprocessing GRACE data up to early 2016 based on new, improved GRACE data, with the primary goal to expand the sea level rise curves of the IMBIE study to 2016. 
The successful GRACE gravity field mission (Tapley et al., 2004) has since late 2002 provided measurements of the temporal variations of the gravitational field of the Earth in the form of monthly expansions of the gravitational field in spherical harmonics (Bettadpur, 2003). These data have provided a unique way to monitor the changing ice sheets of the Earth, and their link with climate change. GRACE measurements have clearly documented the accelerating mass loss of the Greenland ice sheet, with early results of analysis (e.g., Velicogna and Wahr 2006, Horwath and Dietriech, 2006, Chen et al, 2006, Lutsche et al 2006, Forsberg and Reeh, 2007) giving quite variable results in the 150-250 GT/yr range, depending on the analyzed period (for examples see Table 1).

Recent comprehensive multiple-method "reconciled" estimates (Shepherd et al, 2012: Sasgen et al. 2012) give results in a more narrow band around -225 GT/yr for Greenland, and -85 GT/yr for Antarctica, for the period 2003-11. Depending on the time periods analyzed, the mass loss trend estimates tend to increase with time, as the melt of both Greenland and especially Antarctica shows accelerating signals.

Differences in the published GRACE mass loss estimates are mainly due to method differences in how to convert the monthly gravity field solutions (expressed as spherical harmonic expansions, also termed "Level-2" GRACE data) into surface mass changes. The limited spatial resolution of GRACE (around 300-350 km), differences in processing methods adopted by the different Level-2 data centers, differences in data corrections, notably the glacial isostatic adjustment (GIA) process, and leakage of GRACE signals between different mass bodies, are major sources of differences. The nature of most of these error sources are explained in details in the fundamental pre-launch GRACE methodology paper (Wahr et al., 1998). The same paper also outlined spherical harmonic filtering and conversion methods for converting GRACE spherical harmonic data into mass change estimates.

The point mass inversion methods used in this paper are fundamentally different from the spherical harmonic conversion methods of the above pre-launch paper. In the point mass (or mascon) methods, a direct inversion of the measured signals at orbit altitude are converted into associated mass distributions at the Earth's surface. This can either be done by direct global analysis of "raw" GRACE satellite to satellite ranging data (termed "Level-1" data), solving for global mascons (e.g., Luthke et al., 2006, 2013), or by solving for regional distributions of mascons, e.g. representing ice covered areas, as done by e.g. (Forsberg and Reeh, 2006; Baur and Sneeuw, 2011; Barletta et al., 2012). In the regional point mass estimation methods, a priori knowledge of the 
source region of the mass changes can be taken into account in a simple intuitive manner, but with the risk of increasing "leakage" from unmodelled land and ocean mass changes close to the icesheet. The IMBIE project has, however, confirmed that estimates by either methods in Greenland and Antarctica provide similar results, when applied to same periods and using the same auxillary geophysical and environmental corrections.

We present in the sequel a reanalysis of a new 13.5-year GRACE data set from an improved unconstrained Kalman filter processing scheme at ITSG/TU Graz (Mayer-Gürr et al., 2014; Klinger et al., 2016), giving a clear picture of the year-to-year mass change signals, and the regions of greater mass loss, and providing an extension of the IMBIE (Shepherd et al., 2012) estimates of sea level rise due to ice sheet melt. We additionally supplement the GRACE analysis for Greenland and Antarctica, with mass change results from satellite altimetry (EnviSat and CryoSat), using a joint GRACE/altimetry inversion method, to pin-point with greater resolution where current mass changes are taking place. The joint inversion method improves the limited resolution of GRACE. This improved resolution is relatively more important for Greenland rather than for Antarctica, where the role of resolution is less dominant due to the larger area, and where leakage from adjacent ice caps is not an issue.

\section{Basics of analysis of GRACE data}

All GRACE Level-2 data are provided as monthly spherical harmonic geopotential expansions of form

$$
\begin{aligned}
& V(r, \phi, \lambda)=\frac{G M}{R} \sum_{n=2}^{N}\left(\frac{R}{r}\right)^{n} \times \\
& \sum_{m=0}^{n}\left(C_{n m} \cos m \lambda+S_{n m} \sin m \lambda\right) \bar{P}_{n m}(\sin \phi)
\end{aligned}
$$

where $\mathrm{V}$ is the geopotential, $\mathrm{G}$ the gravitational constant, $\mathrm{M}$ earth mass, $\mathrm{R}$ the earth radius, and the fully normalized spherical harmonic coefficients $C_{n m}$ and $S_{n m}$, provided by a processing center, such as CSR (Center for Space Research, University of Texas) or GFZ (Geoforschungscenter, Potsdam), the primary GRACE mission data providers.

We have in our computations, however, used new reprocessed Level-2 data provided by Institute for Theoretical and Satellite Geodesy, TU Graz (ITSG), to harmonic degree and order 90 (Klinger et al., 2016). The ITSG GRACE data appears to be improved relative to corresponding CSR and 
GFZ data, and has recently been adopted for use in the ESA Climate Change Initiative projects for both the Greenland and Antarctica ice sheets, see http://www.esa-icesheets-cci.org/.

The ITSG spherical harmonic coefficients have been supplemented with $\mathrm{C}_{20}$-terms from satellite laser ranging derived from the International Laser Ranging Service data (available at https://podaac.jpl.nasa.gov/), and corrections for geocenter mass variations $\left(\mathrm{C}_{10}, \mathrm{C}_{11}, \mathrm{~S}_{11}\right)$ by the method of Swenson et al. (2008), as provided at http://grace.jpl.nasa.gov/. The spherical harmonic coefficients are further modified for the elastic response of the earths crust to a mass load change, which gives an indirect effect on the gravity response. We take this into account in the mass inversion method by modifying the GRACE coefficients for elastic loading by

$$
C_{n m}^{*}=\frac{1}{1+k_{n}} C_{n m} \quad S_{n m}^{*}=\frac{1}{1+k_{n}} S_{n m}
$$

where $k_{n}$ are the elastic Love numbers, using PREM numbers as listed in Wahr et al (1998).

The GRACE spherical harmonic data, as corrected above, should then in principle represent the land ice, land hydrology, GIA mass changes, and other geodynamic/earthquake effects, as atmosphere and ocean mass changes are modelled and subtracted from the original Level-2 coefficient data. In the case of Greenland and Antarctica, the role of land hydrology is small to negligible, especially on temporal trends, and land hydrology effects from the ice-free part of Greenland and Antarctica have thus been ignored in this study.

An important further correction is the GIA effect. Many different past deglaciation history and earth models have been used to infer the GIA effects in Greenland and Antarctica. We use here two "standard" models, namely the ICE-5G model for Greenland (Peltier, 2004), and the W12 model for Antarctica (Whitehouse et al, 2012), as also used in the IMBIE study. The GIA models are also given as spherical harmonic models. We will not discuss further the possible errors in these models, but only note that the relatively large error quoted in the IMBIE estimates ( \pm 25 GT for Greenland and \pm 50 GT for Antarctica) are predominantly due to the GIA effects.

The results for the observed GRACE gravity trends at satellite altitude for Greenland and Antarctica over the period April 2002 to Jan 2016 (with a total of 148 available monthly epochs) are shown in Fig. 2. Because of the monthly "stacking" of data to estimate a trend, the use of "destriping" filters (Kusche et al., 2009), commonly in use for attenuating the dominant north-south trending error patterns in GRACE data (due to the near-polar orbit), seems not to be needed. No 
further filtering has thus been applied to the gravity trend data. Fig. 2 shows major signals associated with the margins and major outlet glaciers in Greenland, and for Antarctica the overall dominating signal over the Amundsen Sea Embayment glacier systems in West Antarctica.

\section{Generalized inverse point mass inversion for Greenland and Antarctica changes}

From the fitted GRACE trends, cf. Fig. 2, a trend of mass change at the Earth' surface can be obtained by a linear, albeit ill-posed inversion procedure. The formula for the response function for this inversion can be found in Heiskanen and Moritz (1967). For a point mass $j$ at the surface, the gravity attraction at orbit height location $i$ is of form

$$
\delta g_{i}=G m_{j} \frac{R^{2} r-R^{3} \cos \psi}{\left[r^{2}+R^{2}-2 R r \cos \psi\right]^{3 / 2}}
$$

where $\psi$ is the spherical distance, $\mathrm{R}$ the earth radius and $\mathrm{r} \sim \mathrm{R}+480 \mathrm{~km}$ the GRACE orbit altitude (the GRACE orbit has decayed slightly over the years, so $r$ is not constant).

In the inversion method the observed gravity $\delta g_{i}$ values (relative to a mean value over the GRACE period) over the region at GRACE orbit altitude, are combined in the observation vector $y$

$$
\underline{y}=\left\{\delta g_{i}\right\}, i=1, \ldots, n
$$

and modelled by a dense set of point masses $m_{j}$ in a solution vector $x$

$$
\underline{x}=\left\{m_{j}\right\}, j=1, \ldots, m
$$

located at the surface of the ice covered region to be studied. The key element of the method is that point masses are only located where the ice sheet changes are assumed to take place (defined by an “indicator" grid, cf. Fig 3); ocean and ice-free land gravity field changes are assumed to be removed by GIA, ocean and hydrological corrections prior to applying the inversion.

Using an ice-only set of point mass (mascon) elements has both advantages and drawbacks. An advantage is that a priori knowledge of the ice sheet location is applied, but a drawback is that any 
change signals from nearby non-glacial sources (e.g., land hydrology or ocean model errors) are "leaking" into the ice mass change, likely to a larger degree than in the spherical harmonics approach. To avoid such leakage, neighbouring ice caps in Greenland (especially the Canadian ice caps) need to be modelled simultaneously, otherwise the Canadian ice cap changes would "leak" into Greenland, and give too high mass loss estimates there.

The elements of the basic point mass equation (3) form a response matrix A, where the linear observation equations

$$
\underline{y}=A \underline{x}
$$

may be solved by Tychonov generalized inverse by

$$
\underline{x}=\left[A^{T} A+\lambda I\right]^{-1} A T_{\underline{y}}
$$

Here $I$ is the unit matrix and $\lambda$ a regularization factor, needed to obtain a non-singular inversion problem. The $\lambda$-factor determines the necessary trade off between model smoothness and residuals; the total mass change of the Greenland ice sheet will only to a small degree be affected by the choice of $\lambda$; the areal shape of the modelled mass change is, however, stronger affected by this choice. The selection of the optimal $\lambda$-parameter has been discussed at length in Baur and Sneeuw (2011), and will in the end be up to a subjective trade-off.

Linear equations like (7) are readily and quickly solved by the Cholesky method for positive definite linear equation systems. The equations may either be solved for gravity trends, or - on a monthly by monthly basis - by gravity residuals relative to the mean of the period. The latter will give a time series of the mass balance. Because the geometry of the input (a regular grid, covering the region of interest) and the output (a fixed set of space domain masses, covering the ice sheets), the normal equation matrix of (7) will be constant, except for the "right hand side" $\left(A^{T} \underline{y}\right)$ observations. Processing many epochs is therefore extremely fast, as the Cholesky factorization need to be done only once.

Fig. 4 shows the results of the selected point mass solution by the inversion method, using a relatively weak regularization (small $\lambda$-factor), and a 200-250 km cut-away zone for GRACE observations beyond the ice sheets (to limit leakage from oceans and land areas); the resolution of the mass cells are around $50 \mathrm{~km}\left(0.5^{\circ} \times 1^{\circ}\right.$ for Greenland and $0.5^{\circ} \times 2^{\circ}$ for Antarctica $)$. It is seen that the mass balance, expressed in mm water-equivalent change, is negative in a quite narrow band 
along the ice margins in Greenland, in good accordance with in situ and airborne observations (Krabill et al., 2010; Sørensen et al., 2011, Helm et al., 2014), and that the Antarctica changes are dominated by the West Antarctica sector of the Amundsen Sea, with the major changes in the region of the Pine Island / Thwaites glacier systems.

Fig. 5 shows the time series for the Greenland and Antarctic ice sheets, with no time-domain low-pass filtering done on the monthly estimates. Included in the Greenland plot are also results from the northern Canadian ice caps (Ellesmere and Devon Islands), estimated jointly with Greenland. It should be noted, though, that the estimates from the northern Canadian ice caps are further affected by leakage error from the southern Canadian ice caps and glaciers of Baffin and Bylot Island, so the quoted estimates for Ellesmere and Devon Islands are likely too large (and not really a topic for this paper). The estimated mass trends and associated global sea level rise are additionally listed in Table 2 .

It should be noted that the Greenland ice loss estimates include minor outlying ice caps and glaciers; the mass loss of the outlying ice bodies have been estimated at $-28 \pm 11 \mathrm{GT} / \mathrm{yr}$ from ICESat altimetry in the period 2003-8 (Bolsch et al., 2013); this estimate might be slightly overestimated, as it includes a major part of the ice sheet classified as "outlying" (the central East Greenland nunatak zone); the estimate will most likely be an underestimate for more recent periods, where many outlying ice caps and outlet glaciers have experienced rapid melt.

Fig. 5 shows that the mass loss of both Greenland and the northern Canadian ice caps are accelerating, with summer 2012 seeing an exceptionally large melt event in Greenland, and the Canadian ice caps experiencing rapid acceleration since 2008. But it is also seen that taking a trend over only the last 5 years gives an apparent slow-down of the Greenland ice sheet melt, following the anomalous large melt event of 2012 (Nghiem et al, 2012). In July 2012 the entire Greenland ice sheet for the first time in recent times experienced melt and rain even at the highest elevations, due to unsual warm meterorological conditions; using a five-year trend interval don't make too much sense because of the highly unusual events of recent years, where the 2012 summer was followed by an unusually cold 2013 summer.

For Antarctica a major apparent acceleration is seen continent-wide, especially due to the West Antarctica ice streams, with major snow accumulation effects in East Antarctica offsetting to some degree the acceleration in West Antarctica, as studied in more details in Shepherd et al. (2012) and Lenaerts et al. (2013). 
Table 1. Mass change and global sea level rise for Greenland and Antarctica from GRACE

\begin{tabular}{|l|c|c|c|c|c|c|}
\hline \multirow{2}{*}{ Time period } & \multicolumn{2}{|c|}{$\begin{array}{c}\text { Apr 2002-15 } \\
(13.7 \mathrm{yrs})\end{array}$} & \multicolumn{2}{c|}{$\begin{array}{c}\mathbf{2 0 0 6}-15 \\
(10 \text { years })\end{array}$} & \multicolumn{2}{c|}{$\begin{array}{c}\mathbf{2 0 1 1 - 1 5} \\
\text { (5 years })\end{array}$} \\
\cline { 2 - 7 } & $\mathrm{GT} / \mathrm{yr}$ & $\mathrm{mm} / \mathrm{yr}$ & $\mathrm{GT} / \mathrm{yr}$ & $\mathrm{mm} / \mathrm{yr}$ & $\mathrm{GT} / \mathrm{yr}$ & $\mathrm{mm} / \mathrm{yr}$ \\
\hline Greenland, including outlying ice caps $( \pm 25 \mathrm{GT} / \mathrm{yr})$ & -264 & -0.72 & -295 & -0.80 & -265 & -0.72 \\
\hline Ellesmere and Devon Island** $( \pm 20 \mathrm{GT} / \mathrm{yr})$ & -41 & -0.11 & -48 & -0.13 & -45 & -0.12 \\
\hline Antarctica* $( \pm 50 \mathrm{GT} / \mathrm{yr})$ & -92 & -0.25 & -120 & -0.33 & -147 & -0.40 \\
\hline
\end{tabular}

* Two anomalous first epochs (April-May 2012) in GRACE time series deleted. ** Estimates include leakage from Baffin Island

\section{Satellite altimetry used to outline detailed melt regions in Greenland and Antarctica}

In this section we use an extension of the inversion method to include satellite altimetry in the mass loss determination. In Greenland the relatively smaller size of the region (compared to Antarctica) makes the lack of GRACE resolution issue more serious, in terms of pinpointing the true regions of mass loss.

We use for Greenland elevation changes derived from the ESA EnviSat radar altimetry mission (www.esa.int/envisat) for the period 2002-10, generated by a repeat-track algorithm (Sørensen et al., 2015); for the period July 2010-February 2015 we use data from the ESA CryoSat-2 mission (www.esa.int/cryosat), in classical altimeter mode (LRM) in the interior of the ice sheet, and SAR interferometry (SARIn) in the coast-near region. The CryoSat data used are retracked by a novel threshold retracker, and the LRM mode data relocated by an updated Greenland DEM (Nilsson et al., 2016).

CryoSat elevation change estimates are computed by monthly binning and stacking elevation residuals relative to an initial Greenland DEM, with bias and trend estimated in $5 \mathrm{~km}$ resolution cells by "stacking" of the monthly average residuals. The biases of these residuals are subsequently used to update the DEM, and then repeating the stacking process for the final $d h / d t$ results. Both the EnviSat and CryoSat changes are spatially filtered at resolutions around $15-20 \mathrm{~km}$ for the final results.

For Antarctica a similar CryoSat stacking has been performed for a 5-year period July 2010-June 2016, starting from the BEDMAP-2 DEM (Fretwell et al., 2012), using the newest Baseline C ESA Level 2 data (OCOG retracker and DEM-relocation corrected for LRM). The Antarctica elevation changes from the altimetry are shown in Fig 6, along with the corresponding GRACE change data. 
The inversion method outlined in Sect. 3 may also include height change estimates from altimetry. In the joint inversion method an additional set of observation equations for $\underline{x}$ may be formed simply for the trends over the designated period by

$$
\delta g_{i} / d t=\rho_{\text {model }(i)} d h_{i} / d t+f_{i}
$$

where $f_{i}$ is a firn (upper snow layer) compaction correction, and $\rho_{\text {model }}$ a modelled surface density (for more details see Sørensen et al., 2011, or Simonsen et al., 2013). The surface density would typically be ice density of $0.92 \mathrm{~g} / \mathrm{cm}^{3}$ in the margin-near ablation zone, and have lower values of 0.3-0.4 g/ $\mathrm{cm}^{3}$ for uncompacted snow at the higher elevations (Sørensen et al., 2011).

The firn model for Greenland is derived from the regional climate model HIRHAM, run by the Danish Meteorological Institute (R. Mottram, pers.comm.; Simonsen, 2013). An example of the firn compaction correction (for the EnviSat period) is shown in Fig. 7 (left), along with the results of the "optimal” combined altimetry/GRACE combination. The GRACE/altimetry inversion in Greenland is performed using the CryoSat-2 or EnviSat derived mass change estimates at a $25 \mathrm{~km}$ resolution UTM (Universal Transverse Mercator) grid, covering the entire Greenland ice sheet and peripheral ice caps and glaciers (the UTM projection is superior to the often used Polar Stereographic projection in Greenland, giving fewer observation cells and smaller scale distortion corrections). The degrees of freedom in the inversion process include the $\lambda$-factor (7) as well as the apriori standard deviations of both GRACE and altimetry data, with a "best" weighting scheme reproducing the overall GRACE mass loss estimate, while keeping the detailed spatial resolution of the altimetry.

For Antarctica the inversion method has been applied with ice density $0.92 \mathrm{~g} / \mathrm{cm}^{3}$ only; then the inversion method will effectively estimate on overall mass product consistent with GRACE, within the shape parameter of CryoSat; a derived a posteriori regional scale correction to $d h / d t$ would thus represent a kind of proxy for a composite of density variations and firn compaction parameters. The Antarctica inversion was done on a $40 \mathrm{~km}$ resolution polarstereographic grid. The results are shown in Fig. 8, and it is seen that due to larger size of the Antarctica continent relative to Greenland, the difference between the "pure" and "combined" GRACE solutions are relatively smaller.

The overall mass change of the joint estimation methods for both Greenland and Antarctica are within a few GT/yr of the overall GRACE-only mass change estimate. The small variation is due to the strong adjustment constraint from GRACE (the firn model corrections to the Greenland 
altimetry are by themselves around $40 \mathrm{GT} / \mathrm{yr}$ ). The strong GRACE constraint also overcomes the lack of data in altimetry solutions over the most sloping parts of the ice sheets.

\section{Discussion and conclusions}

The mass changes in Greenland are clearly seen to be associated with relatively narrow marginal ice zones, especially in West and South-East Greenland, and major outlet glaciers such as Jakobshavn and Helheim glaciers, most clearly seen in the joint GRACE/altimetry inversion results. The overall mass loss of Greenland is accelerating, but the last 6 years (2010-2015) have seen large year-to-year interannual variations, with 2010 and especially 2012 record melt years. The period 2010-15 has an apparent decreasing trend relative to 2005-2010, which might not be significant due to the short period, the large melt events, and the lack of some key monthly GRACE data (the GRACE satellite pair is now operating way beyond its original design life time).

The large Greenland melt event in 2012 have made the use of radar altimetry for height and mass change estimation more complicated, with inherent changes in melt-generated ice layers inside the upper layers of the firn, leading to "noisy" CryoSat elevation change data, apparent in Fig. 6 (Nilsson et al., 2015; Forsberg et al., 2013) .

For Antarctica, the GRACE time series shows a clear acceleration between 2002 and present, dominated by the West Antarctica outlet glaciers of the Amundsen Embayment (Thwaites and Pine Island glacier systems), but also mass loss in the Antarctic Peninsula and in smaller outlet glacier regions of coastal East Antarctica near $120^{\circ} \mathrm{E}$ (Totten Glacier region). The larger size of the continent give a larger degree of similarity of the jointly estimated altimetry/GRACE mass changes, relative to the GRACE-alone estimates. A major apparent mass increase in Queen Maud Land, East Antarctica, are most likely expressions of the major snowfall events in the region after 2009-2011, which has been estimated to give a mass gain on the order of 350 GT in East Antarctica (Boening et al., 2012; Lenaearts et al., 2013).

The overall GRACE-derived sea level change from the ice sheets are plotted alongside the results of the IMBIE 2012 reconciled estimates of Greenland and Antarctica mass changes in Fig. 9. The IMBIE results are from combinations of altimetry, GRACE and input-output SAR interferometry methods, and therefore do not agree exactly with the GRACE-only solutions of this paper. Furthermore the reprocessed GRACE results 2002-16 have improved significantly since the IMBIE study. The accumulated global sea level rise during the IMBIE period seems to agree reasonably 
well for Greenland, albeit with a slightly lower trend in Antarctica (which might be due to the difference in GIA models used). Beyond the IMBIE period, Fig. 9 shows the extension of the global sea level curve, giving a present (2016) accumulated sea level rise of $12 \mathrm{~mm}$ for Greenland, and 5 mm for Antarctica since the IMBIE starting time of 1992, continuing currently at rates around -0.8 $\mathrm{mm} / \mathrm{yr}$ for Greenland and $-0.4 \mathrm{~mm} /$ year for Antarctica.

\section{Acknowledgements}

The sea level "fingerprinting" plots in Fig. 1 was provided by V. Barletta. Many comments by Anny Cazenave improved the original manuscript. Johan Nilsson, former ph.d. student at DTU Space, now at NASA-JPL, provided the retracked CryoSat-2 data for Greenland. Torsten MayrGürr, TU Graz, provided early access to the new ITSG-processed GRACE L2 data.

\section{References}

Barletta V R, L Sandberg Sørensen and R Forsberg: Variability of mass changes at basin scale for Greenland and Antarctica, The Cryosphere, 6, 3397-3446, 2012, doi:10.5194/tcd-6-3397-2012.

Baur O, N Sneeuw, Assessing Greenland ice mass loss by means of point-mass modeling: a viable methodology. Journal of Geodesy 85, 607-615, 2011. doi:10.1007/s00190-011-0463-1

Bettadpur, S: GRACE level-2 gravity field product user handbook. CSR Publ. GR-03-01, Univ. of Texas, Austin, http://podaac.jpl.nasa.gov/grace, 2003.

Boening C, M Lebsock, F Landerer, G Stephens: Snowfall-driven mass change on the East Antarctic ice sheet. The Cryosphere, Volume 39, Issue 21, 2012, doi: 10.1029/2012GL053316

Bolsch, T, L. Sandberg Sørensen, S. B. Simonsen, N. Mölg, H. MacGuth, P. Rastner, F. Paul: Mass loss of Greenland's glaciers and ice caps 2003-8 revealed from ICESat laser altimetry data. Geophys. Res. Lett.,40 (5), 875-881, 2013, doi:10.1002/grl.50270.

Dieng, H B, N Champollion, Y Wada, E Schrama, B Meyssignac: Total land water storage change over 2003-13 estimated from a global mass budget approach. Environ. Res. Lett., 10, 124010, 2015, doi:10.1088/1748-9326/10/12/124010

Ewert H, Groh A and Dietrich R: Volume and mass changes of the Greenland ice sheet inferred from ICESat and GRACE. J. Geodyn. 59-60 111-23, 2012.

Forsberg, R and N Reeh: Mass Change of the Greenland Ice Sheet from Grace. In: Proceedings of the $1^{\text {st }}$ international symposium of the IGFS, Harita Dergisi, Ankara, vol. 18, pp. 454-458, 2007.

Forsberg R, L Sørensen, J Levinsen, J Nilsson: Mass loss of Greenland from GRACE, IceSat and CryoSat. Proceedings of the CryoSat Workshop, Dresden, March 2013. ESA Special Publication 717 paper S6-4. 
Fretwell P, H D Pritchard, D G Vaughan, J L Bamber, N E Barrand, R. Bell, C. Bianchi, R G Bingham, D D Blankenship, G Casassa, G Catania, D Callens, H Conway, A J Cook, H Corr, D Damaske, V Damm, F Ferraccioli, R Forsberg, S Fujita, P Gogineni, J A Griggs, R Hindmarsh, P Holmlund, J Holt, R W Jacobel, A Jenkins, W Jokat, T Jordan, E C King, J Kohler, W Krabill, M Riger-Kusk, K Langley, G Leitchenkov, C Leuschen, B Luyendyk, K Matsuoka, Y Nogi, O Nost, S Popov, E Rignot, D Rippin, A Riviera, J Roberts, N Ross, M Siegert, A Smith, D Steinhage, M Studinger, B Sun, B Tinto, B Welch, D Young, C Xiangbin, A Zirizzotti: BEDMAP2: Improved Ice Bed, Surface and Thickness Datasets for Antarctica. The Cryosphere, 6, 4305-4361, doi:10.5194/tcd-6-4305-2012, 2012.

Groh A, Ewert H, Fritsche M, Rülke A, Rosenau R, Scheinert M and Dietrich R: Assessing the current evolution of the Greenland ice sheet by means of satellite and ground-based observations Surv. Geophys. 35 1459-80, 2014.

Heiskanen, W and H Moritz: Physical Geodesy. Wheeler, San Franciso, 1967.

Helm V, Humbert A and Miller H: Elevation and elevation change of Greenland and Antarctica derived from CryoSat-2, Cryosphere 8 1539-59, 2014.

Horwath, M and R Dietrich: Errors of regional mass variations inferred from GRACE monthly solutions. Geoph. Res. Lett., 33, L07502, doi:10.1029/2005GL025550, 2006.

Holland, D.M., R.H. Thomas, B. deYoung, M.H. Ribergaard, and B. Lyberth: Acceleration of Jakobshavn Isbrae Triggered by Warm Subsurface Ocean Waters. Nature Geoscience, 28 September, 2012, doi:10.1038/ngeo316.

Klinger, B, Mayer-Gürr, T, Behzadpour, S, Ellmer, M, Kvas, A \& Zehentner: The new ITSG-Grace2016 release, EGU General Assembly 2016, Vienna, Austria, 2016, doi: 10.13140/RG.2.1.1856.7280

Krabill, W, W Abdalati, E Frederick, S Manizade, C Martin, J Sonntag, R Swift, R Thomas, W Wright, J Yungel: Greenland Ice Sheet: High-Elevation Balance and Peripheral Thinning. Science, 289, pp. 428430, 2000.

Kusche, J., R. Schmidt, S. Petrovic, and R. Rietbroek: Decorrelated GRACE Time-Variable Gravity Solutions by GFZ, and their Validation using a Hydrological Model, J. Geodesy, 83,903-913, 2009, doi:10.1007/s00190-009-0308-3

Lenaerts, J. T. M.; Van Meijgaard, E.; Van den Broeke, M. R.; Ligtenberg, S. R. M.; Horwath, M.; Isaksson, E.: Recent snowfall anomalies in Dronning Maud Land, East Antarctica, in a historical and future climate perspective; Geophysical Research Letters, doi: 10.1002/grl.50559, 2013

Luthcke S B, Zwally H J, Abdalati W, Rowlands D D, Ray D D, Nerem R S, Lemoine F G, McCarthy J J, Chin D S: Recent Greenland ice mass loss by drainage basin from satellite gravity observations. Science 314, pp 1286-89, doi:10.1126/science.1130776, 2006. 
Luthcke S B, T J Sabaka, B D Loomis, A A Arendt, J.J. Mccarthy, J. Camp: Antarctica, Greenland and Gulf of Alaska land-ice evolution from an iterated GRACE global mascon solution. Journal of Glaciology, Vol. 59, No. 216, 2013, doi:10.3189/2013JoG12J147

Mayer-Gürr, T.; Zehentner, N.; Klinger, B.; Kvas, A., ITSG-Grace2014: a new GRACE gravity field release computed in Graz. - in: GRACE Science Team Meeting (GSTM), Potsdam, Sept. 2014.

McMillan M, A Shepherd, A Sundal, K Briggs, A Muir, A Ridout, A Hogg, D Wingham: Increased ice losses from Antarctica detected by CryoSat-2.Geoph.Res. Lett., 41, 11, pp 899-3905, 2014, doi:10.1002/2014GL060111

Nilsson, J, Vallelonga, P T, Simonsen, S B, Sørensen, L S, Forsberg, R, Dahl-Jensen, D, Hirabayashi, M, Goto-Azuma, K, Hvidberg, CS, Kjær, H A and Satow, K: 'Greenland 2012 melt event effects on CryoSat-2 radar altimetry' Geophysical Research Letters, vol 42, pp. 3919-3926, 2014. doi: 10.1002/2015GL063296.

Nilsson, J, A Gardner, L Sørensen, and R Forsberg: Improved retrieval of land ice topography from CryoSat2 data and its impact for volume change estimation of the Greenland Ice Sheet. The Cryosphere, MS tc2016-109, accepted for publication, 2016.

Nghiem, S V, D. K. Hall, T. L. Mote, M. Tedesco, M. R. Albert, K. Keegan, C. A. Shuman, N. E. DiGirolamo, G. Neumann: The extreme melt across the Greenland ice sheet in 2012. Geophysical Research Letters, vol. 39 no 20, 2012, doi: 10.1029/2012GL053611

Peltier, W R, Global glacial isostasy and the surface of the ice-age earth: The ice-5G (VM2) model and grace. Annual Review of Earth and Planetary Sciences 32, 111 (2004).

Rignot E and Kanagaratnam P: Changes in the velocity structure of the Greenland ice sheet Science 311 986-90, 2006.

Sasgen I, van den Broeke M, Bamber J L, Rignot E, Sørensen L S, Wouters B, Martinec Z, Velicogna I and Simonsen S B: Timing and origin of recent regional ice-mass loss in Greenland Earth Planet. Sci. Lett. 333-334 293-303, 2012.

Simonsen, S B, Stenseng, L, Adalgeirsdottir, G, Fausto, R, Hvidberg, C S, Lucas-Picher, P: Assessing a multilayered dynamic firn-compaction model for Greenland with ASIRAS radar measurements. Journal of Glaciology, 59(215):545-558, 2013.

Shepherd A, E Ivins, G A, and 43 co-authors: A Reconciled Estimate :of Ice Sheet Mass Balance. Science, 338, pp. 2012.

Swenson S C, D P Chambers, and J Wahr: Estimating geocenter variations from a combination of GRACE and ocean model output. J Geophys. Res.-Solid Earth, Vol 113, Issue: B8, Article B08410, . doi:10.1029/2007JB005338, 2008. 
Sørensen, L S, S B Simonsen, K Nielsen, P Lucas-Picher, G Spada, G Adalgeirsdottir, R Forsberg, C Hvidberg:Mass balance of the Greenland ice sheet - a study of ICESat data, surface density and firn compaction modelling, The Cryosphere 5, 173-86, doi:10.5194/tcd-4-2103-2010.

Sørensen, L S, S B Simonsen, R Meister, R Forsberg, J Levinsen, T Flament: Envisat-derived elevation changes of the Greenland ice sheet, and a comparison with ICESat results in the accumulation area, Remote Sensing of Environment, p. 7, 2015.

Tapley, B D, S Bettadpur, M Watkins, C Reigber: The gravity recovery and climate experiment: Mission overview and early results. Geoph. Res. Lett., 31, L09607, doi:10.1029/2004GL019920, 2004.

Velicogna, I and J Wahr: Acceleration of Greenland ice mass loss in spring 2004. Vol 443, 21 Sep 2006, doi:10.1038/nature05168.

Velicogna I and Wahr J: Time-variable gravity observations of ice sheet mass balance: precision and limitations of the GRACE satellite data Geophys. Res. Lett. 40 3055-63, 2013.

Wahr, J, Molenaar M, Bryan F: Time variability of the earths gravity field: hydrological and oceanographic effects and their possible detection by GRACE. J. Geophys. Res., 103, pp 30205-30229, doi:10.1029/98JB02844, 1998.

Whitehouse, P L, M. J. Bentley, A. M. Le Brocq, A deglacial model for Antarctica: geological constraints and glaciological modelling as a basis for a new model of Antarctic glacial isostatic adjustment. Quaternary Science Reviews 32, 1 (2012).

Zwally H J et al 2011 Greenland ice sheet mass balance: distribution of increased mass loss with climate warming; 2003-07 versus 1992-2002 J. Glaciol. 57 88-102 


\section{Figures and figure captions}
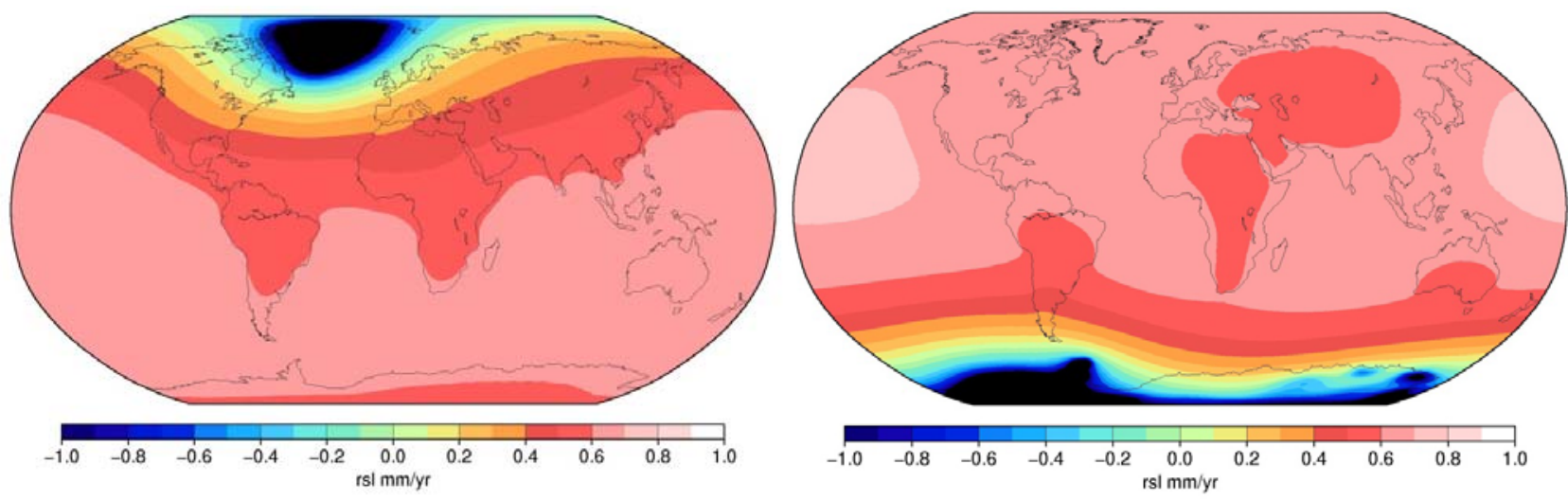

Fig. 1. Relative sea level rise due to Greenland melt (left) and Antarctica melt (right) for IceSat period 2003-8, unit mm/year. Figures courtesy of V. Barletta (DTU Space), produced as part of EU Ice2Sea project.
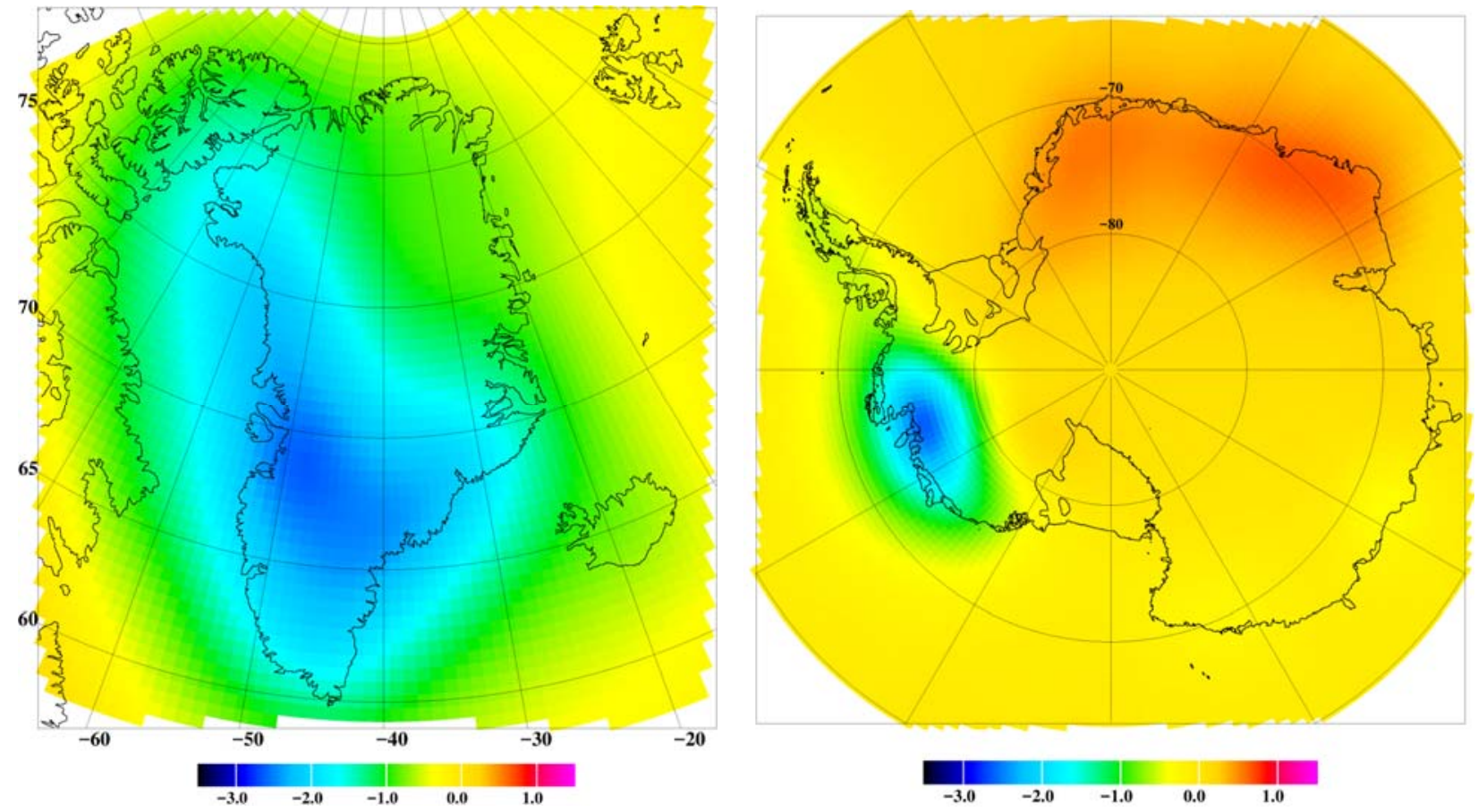

Fig. 2. GRACE gravity change signals 2002-16 over Greenland (left) and Antarctica (right), at orbit altitude. GRACE ITSG-2016 solution to degree $\mathrm{n}=90$, corrected for elastic response. Unit $\mu \mathrm{Gal} / \mathrm{yr}$. 

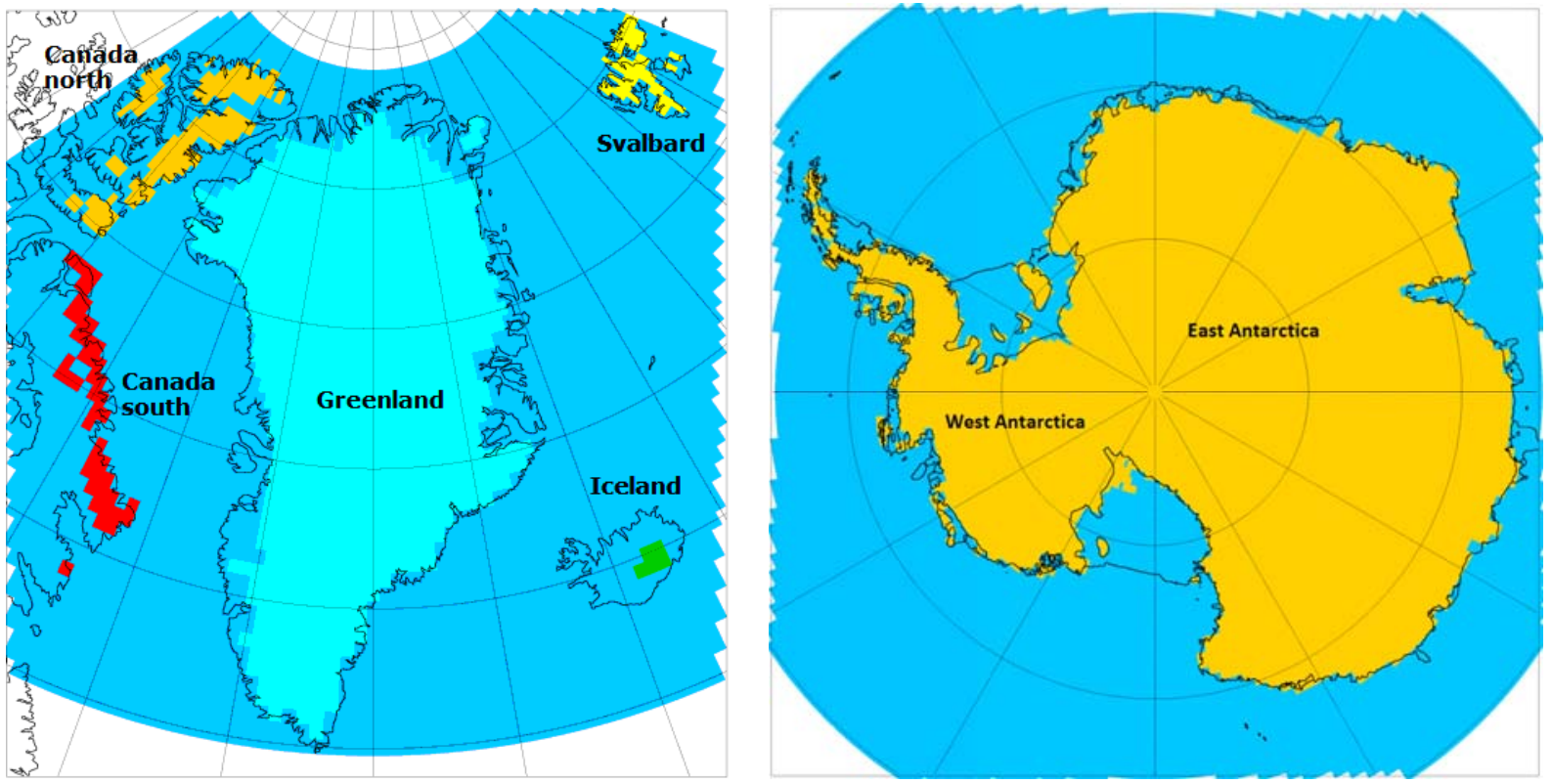

Fig. 3. Indicator grids for the Greenland ice sheet and adjacent ice caps, and for the grounded ice regions of Antarctica. The mascons are distributed at approx. $50 \mathrm{~km}$ resolution. For Greenland only the Ellesmere and Devon Island ("Canada north") are solved for to avoid excess leakage.
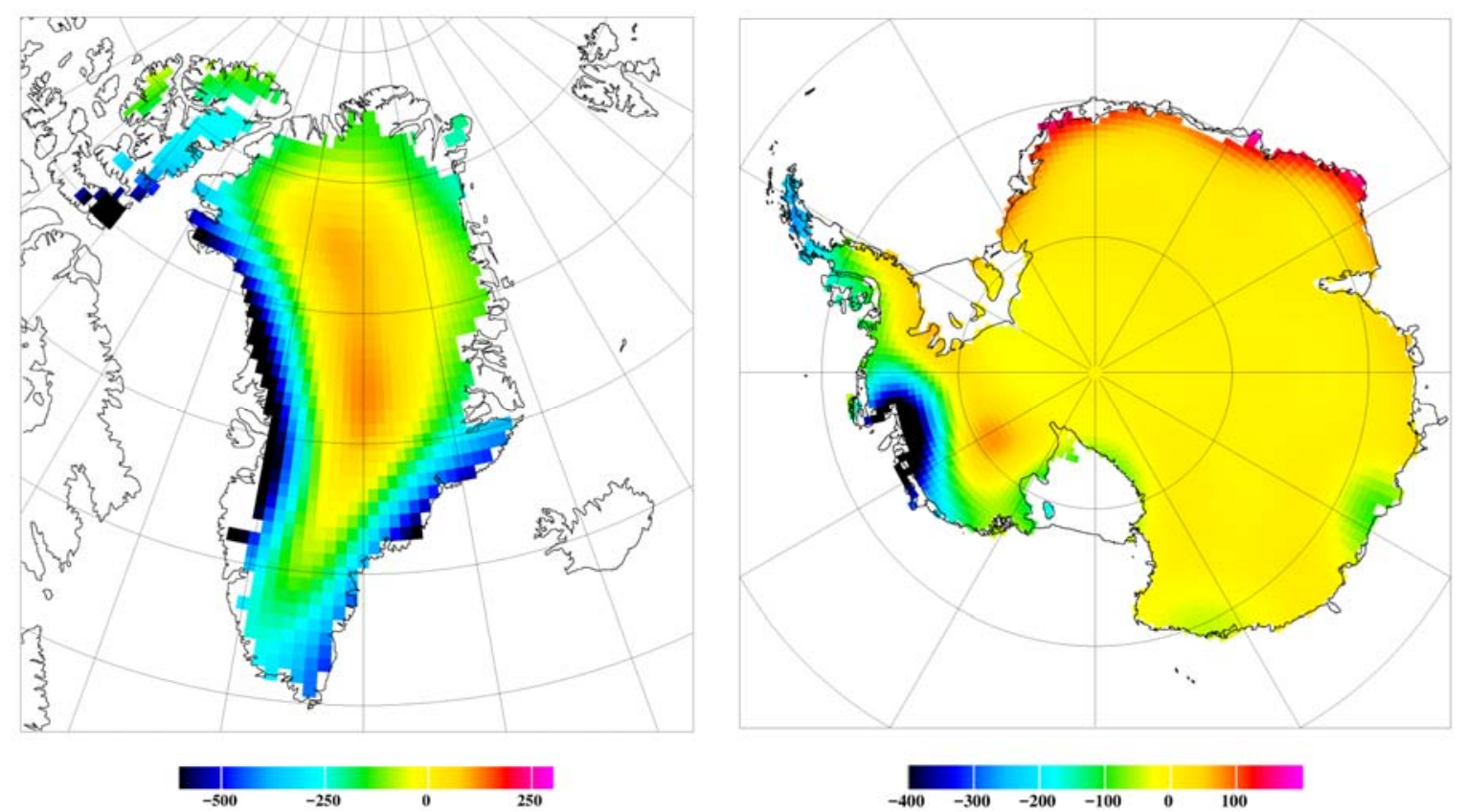

Fig. 4. Mass change trends 2002-16 for Greenland and Antarctica. Unit: mm water-equivalent/year. Note difference in colour scale (and size of the ice sheets, Antarctica map scale only half of Greenland). 

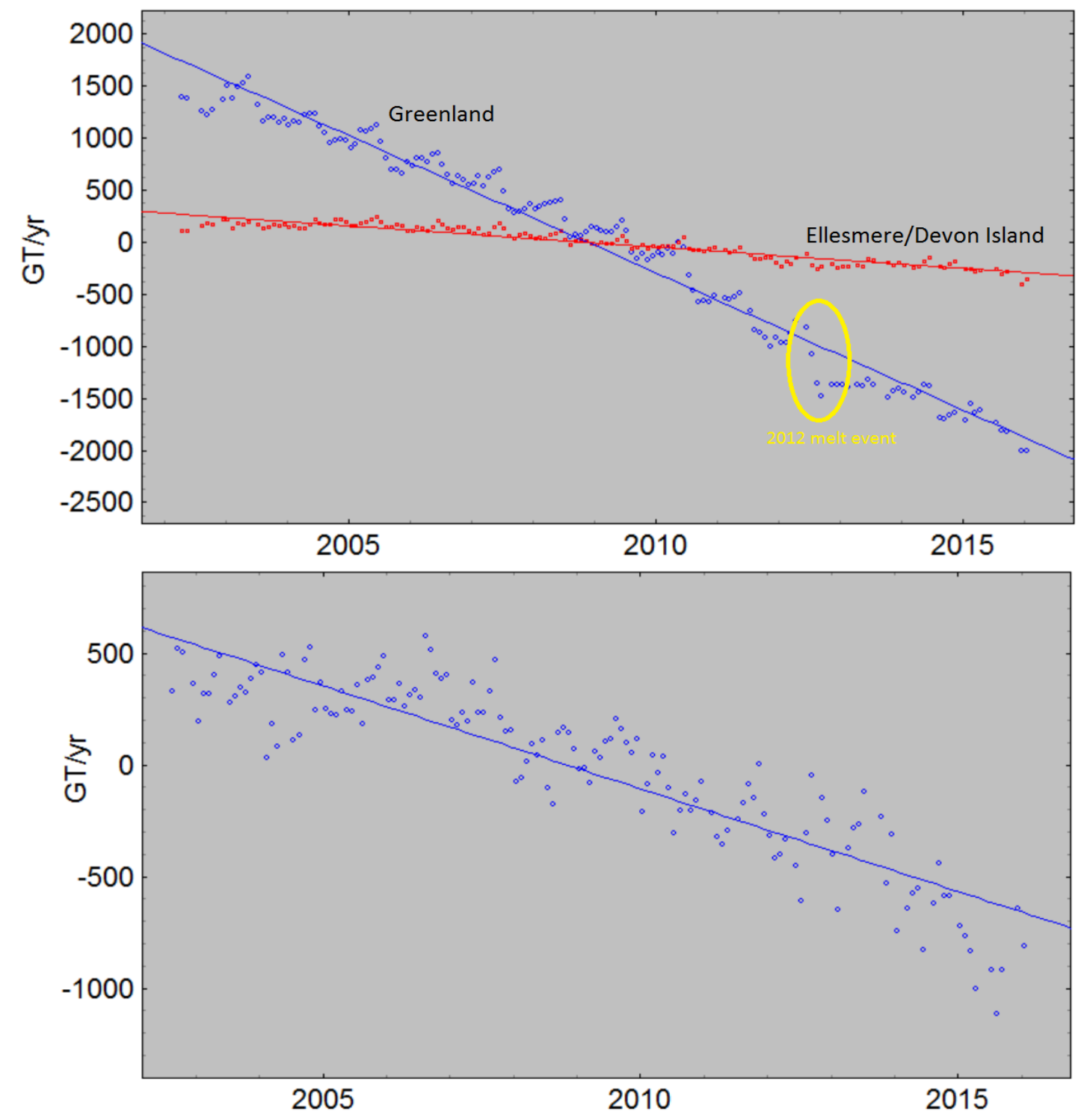

Fig. 5. Unfiltered GRACE time series of mass balance for Greenland and Ellesmere/Devon Island (upper), and Antarctica (lower), with monthly solution values (dots) and linear trend fit. Yellow circle shows 2012 record melt event in Greenland. 

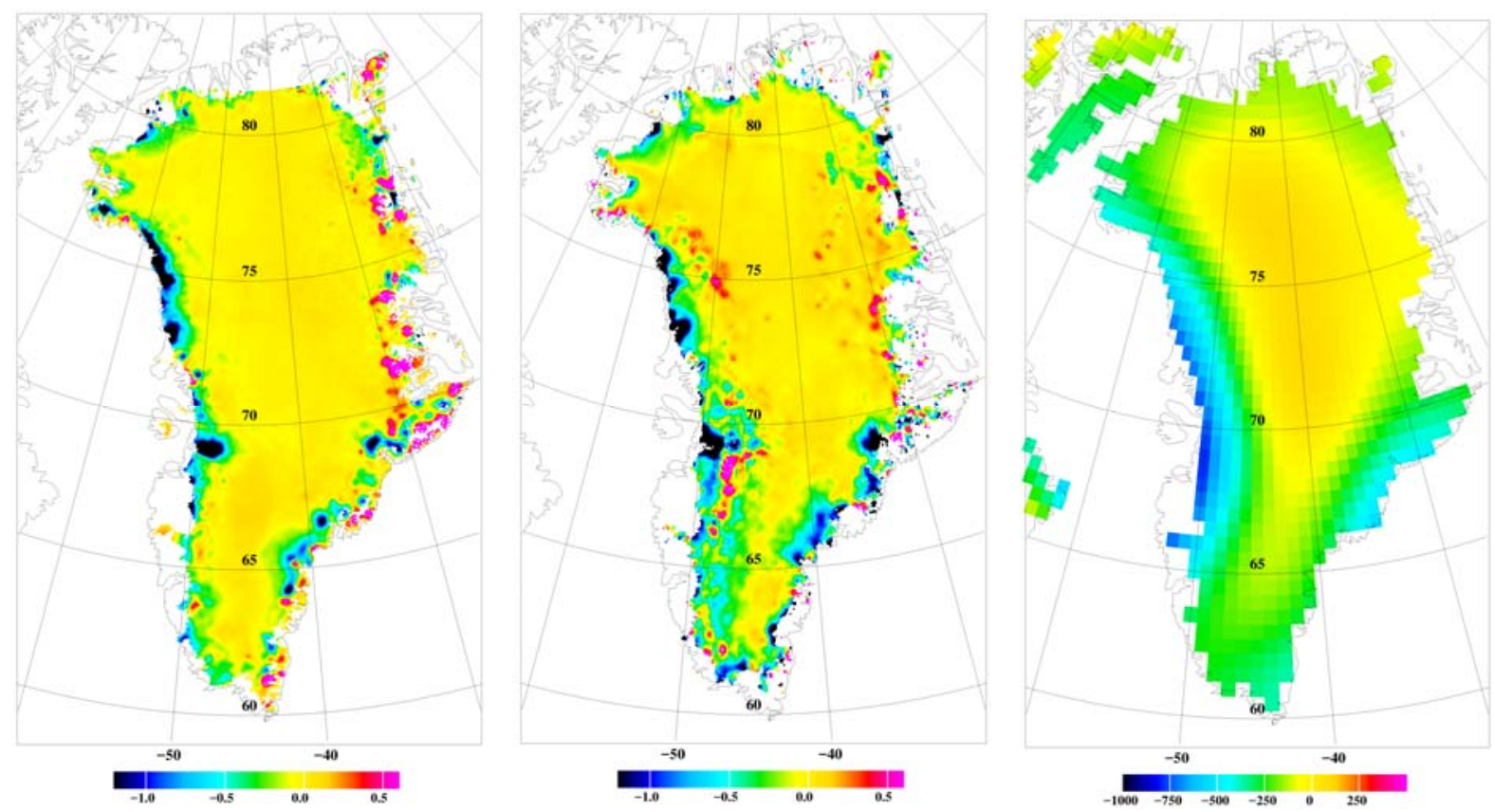

Fig. 6. Elevation changes of the Greenland ice sheet from EnviSat 2002-10 (left), CryoSat 2010-15 (center) and GRACE 2010-15 (right). Units: m/yr for height changes, and mm/year water equivalent for GRACE.
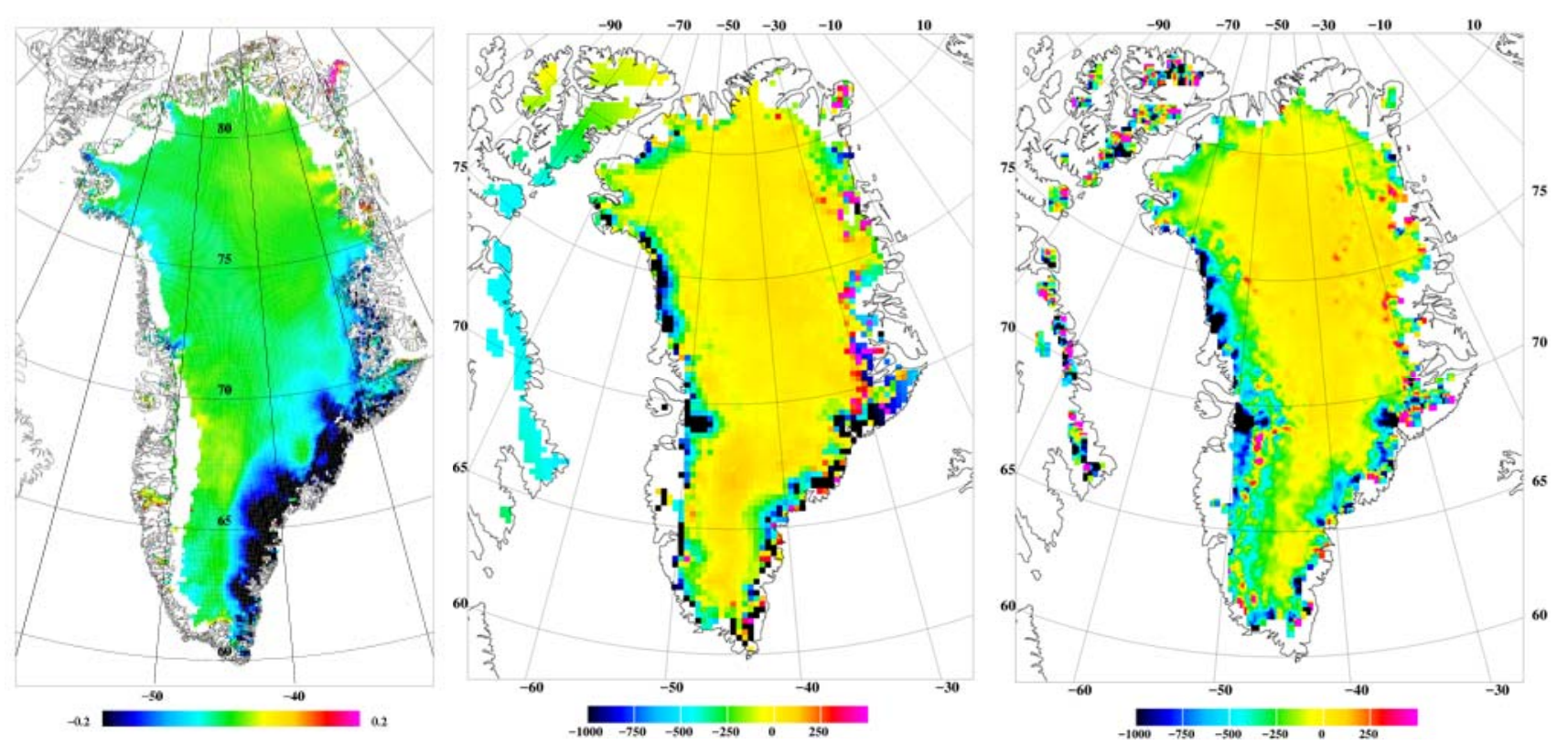

Fig. 7. Left: Average Greenland firn compactions corrections from HIRHAM (unit: m/yr). Center/right: Mass solutions by constrained GRACE inversion with EnviSat (center) and CryoSat (right, including Canadian ice caps), unit mm w.eq./yr. 

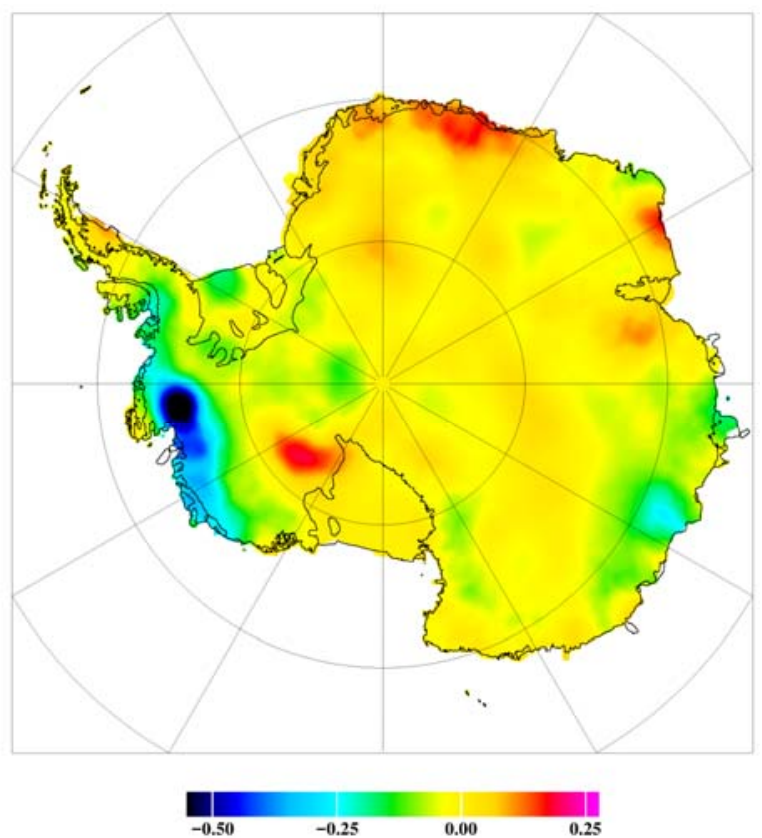
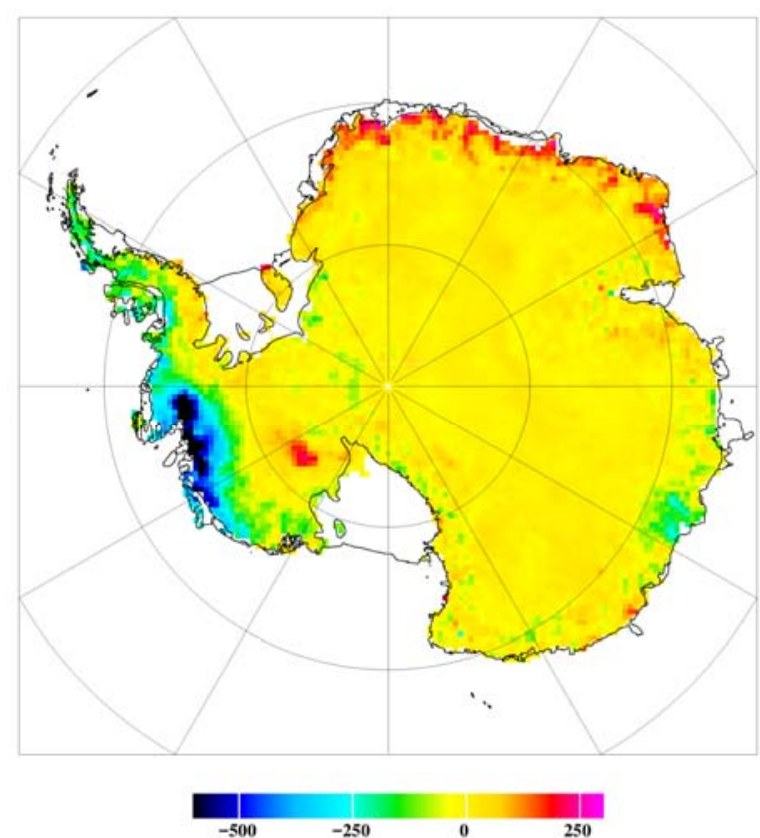

Fig 8. Antarctica elevation changes from CryoSat 2010-15 (left, unit m/year), and jointly estimated GRACE/CryoSat mass changes (right, unit $\mathrm{mm}$ w.eq./year). CryoSat data smoothed to $0.3^{\circ}$ resolution.

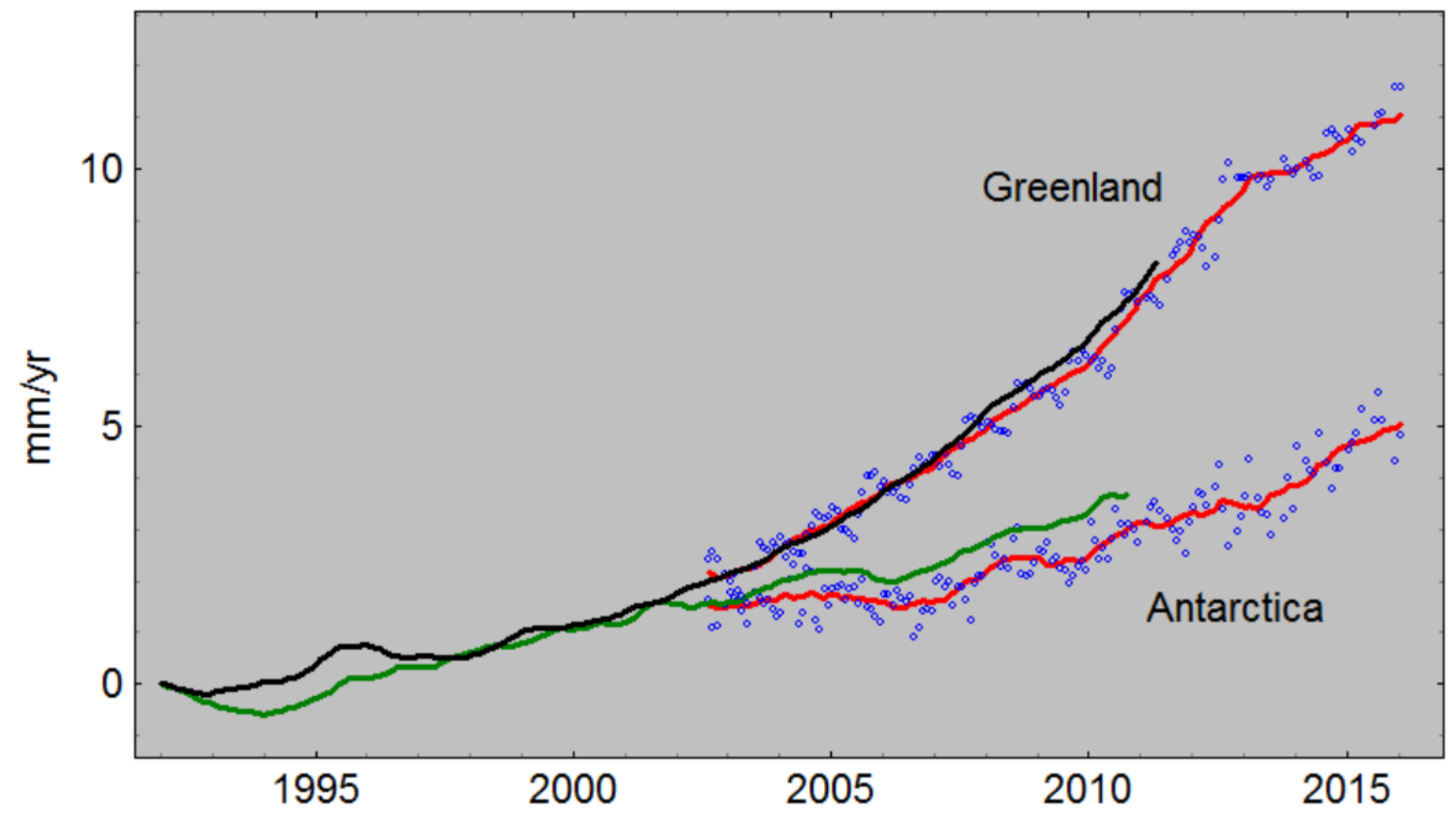


Fig. 9. Accumulated global sea level rise from the ITSG GRACE 2002-16 monthly solutions (blue), with yearly GRACE moving-average filtered values (red), plotted together with IMBIE 1992-2011 Greenland (black) and Antarctica (red) reconciled mass change estimates (Shepherd et al., 2012). 